\title{
Information literacy standards for science and technology A draft
}

\author{
by the ALA/ACRL/STS Task Force on Information Literacy for Science and Technology
}

I nformation literacy competence and the purpose of information literacy competency standards are fully described in the "Information literacy standards for higher education" at www.ala.org/ala/acrl /acrlstandards/standards.pdf. This document (page 4, Section 1:2) states that information literacy "is common to all disciplines, to all learning environments, and to all levels of education."

Information literacy in science and technology disciplines is defined as a set of abilities to identify the need for information, procure the information, evaluate the information, and subsequently revise the strategy for obtaining the information; to use the information and to use it in an ethical and legal manner; and to engage in lifelong learning. Information literacy competence is especially important for students in science and engineering/technology disciplines, who must access a wide variety of information sources that carry the body of knowledge in their fields. These are rapidly changing and advancing fields in which knowledge of how to keep up with new developments is vital to the practicing scientist and engineer. Our objective is to create a document that can be used by science and technology educators, in the context of their institution's mission, to help guide their information literacy-related instruction and to assess student progress.

Based on the "Information Literacy Competency Standards for Higher Education," five standards and twenty-six performance indicators were developed. Each performance indicator is accompanied by one or more outcomes for assessing the progress toward information literacy of students of science and engineering or technology at all levels of higher education.

This document is intended to be a living document with future opportunities for input from the community and is published here for broad professional review of this initial version.

\section{Standard one}

The information literate student determines the nature and extent of the information needed and constructs a course of action for obtaining the information.

\section{Performance indicators}

The information literate student:

1. Defines and articulates the need for information.

Outcomes include:

The student:

- Identifies and/or paraphrases a research topic or other information need.

- Develops a hypothesis or thesis statement and formulates questions based on the information need.

- Explores general information sources to increase familiarity with current knowledge of the topic.

- Defines or modifies the information need to achieve a manageable focus.

- Identifies key concepts and terms that describe the information need.

2. Identifies a variety of types and formats of potential sources for information. 
Outcomes include:

The student:

- Knows how scientific, technical, and related information is formally and informally produced, organized, and disseminated. Understands the flow of scientific information and the scientific information life cycle.

- Understands cultural differences in science-based knowledge systems and in the development of knowledge.

- Differentiates between primary and secondary sources, recognizing how their use and importance vary with each discipline.
- Has a working knowledge of the literature of the field.

- Is aware of the professional associations of the field and their literature.

- Understands sources that are specific to the field, e.g., manuals, handbooks, patents, standards, material/equipment specifications, current rules and regulations, reference material routinely used in industry, manuals of industrial processes and practices, and product literature.

- Recognizes that knowledge can be organized into disciplines and combinations

\section{About the guidelines}

In January 2002, JoAnn DeVries, chair of the Science and Technology Section (STS), charged the STS Task Force on Information Literacy for Science and Technology with developing standards, performance indicators, and outcomes for library instruction in science and technology, based on the "Information Literacy Competency (ILC) Standards for Higher Education."

The STS Council approved the resulting product in June 2004 at the ALA Annual Conference in Orlando, Florida. The STS Task Force identified five standards, with the fifth standard being entirely new and different from the "ILC Standards for Higher Education." The STS standards are also available on the ACRL Web site at www.ala.org/ (click on "Standards and Guidelines").

This work is the product of more than two years of reviewing sources, communication, conference meetings, soliciting reviews through several science/technology electronic lists, and collaboration among the members of the task force who serve as liaison librarians for major science and engineering disciplines. Currently, those members are:

- Virginia Baldwin, University of Nebraska-Lincoln, Engineering, Physics, and Astronomy Librarian, task force chair

- C. J. (Catherine Woodworth) Wong, Quinnipiac University, science librarian

- Sheila Young, Arizona State University, science reference librarian/engineering, on ARL Learning Outcomes Workgroup

- Ibironke Lawal, Virginia Commonwealth University, engineering and science librarian, biotechnology, chemistry, mathematics

- Daureen Nesdill, University of Utah, science and engineering librarian

- Barbara MacAlpine, Trinity University, science librarian

Former members also made contributions to the development of the final product:

- Sherry Durren, Georgia Perimeter College, information literacy librarian

- Jennifer Laherty, California State University-Hayward, biological sciences, chemistry, communicative sciences and disorders, geology, health sciences, and nursing

- Elizabeth I. Hanson, Indiana University, life sciences.

Task force members are grateful for any comments or feedback. Please address your remarks to Virginia Baldwin, task force chair, at vbaldwin2@unl.edu. 
of disciplines (multidisciplinary) that influence the way information is accessed and considers the possibility that the literature of other disciplines may be relevant to the information need.

- Identifies the value and differences of potential resources in a variety of formats (e.g., multimedia, database, Web site, data set, Geographic Information Systems, 3-D technology, open file reports, audiovisual, book, graphs, maps). Realizes that information may need to be constructed with raw data from primary sources.

- Recognizes that potentially useful information or data in a variety of formats may be proprietary, have limited access, or may be freely available online and may require specific data management expertise and an understanding of the structure of agencies involved in producing the information.

- Recognizes the value of archival information, recognizes how its use and importance may vary with each discipline, and recognizes the importance of preservation of information.

- Identifies the purpose and audience of potential resources (e.g., popular vs. scholarly, current vs. historical, external vs. [corporate] internal).

3. Considers the costs and benefits of acquiring the needed information.

Outcomes include:

The student:

- Determines the availability of needed information and makes decisions on broadening the information-seeking process beyond local resources (e.g., through using or consulting with interlibrary loan, nearby facilities, colleagues, independent information brokers).

- Recognizes that there may be a tradeoff between the value of the information and the time and cost to obtain it.

- Formulates a realistic overall plan and timeline to acquire the needed information.

- Recognizes the importance of a variety of information research areas (regarding experts in a field, consultants, revenue op- portunities, licensing opportunities, patent and intellectual property, etc.) for competitive advantage purposes and to avoid being misinformed.

- Recognizes that information needed may be in a foreign language and that translation may be necessary.

\section{Standard two}

The information literate student procures needed information effectively and efficiently.

\section{Performance indicators}

The information literate student:

1. Selects the most appropriate investigative methods or information retrieval systems for accessing the needed information.

Outcomes include:

The student:

- Identifies appropriate investigative methods (e.g., literature search, laboratory experiment, simulation, fieldwork).

- Investigates the scope, content, and organization of information retrieval systems.

- Considers experts or other researchers as potential information resources.

- Selects efficient and effective approaches for accessing the information needed from the investigative method or information retrieval system.

2. Constructs and implements effectively designed search strategies.

Outcomes include:

The student:

- Develops a research plan appropriate to the investigative method.

- Identifies keywords, synonyms, and related terms for the information need.

- Selects controlled vocabulary specific to the discipline or information retrieval system.

- Uses other methods of search term input, such as structure searching and image searching, specific to the discipline or information retrieval system.

- Constructs a search strategy using appropriate commands for the information retrieval system selected (e.g., Boolean op- 
erators, truncation, and proximity for search engines; and internal organizers, such as indexes for books).

- Implements the search strategy in various information retrieval systems using different user interfaces and search engines, with different command languages, protocols, and search parameters.

- Follows citations and cited references to obtain additional, pertinent articles.

- Recognizes similar features among different interfaces (such as: print, e-mail, and save options; search fields; and controlled vocabulary).

3. Retrieves information using a variety of methods.

Outcomes include:

The student:

- Uses various relevant search systems to retrieve information in a variety of formats.

- Has a basic knowledge of how a typical disciplinary library is organized and uses various classification schemes and other systems (e.g., call number systems or indexes) to locate information resources within the library or to identify specific sites for physical exploration.

- Uses specialized online or in-person services to retrieve information needed (e.g., interlibrary loan/document delivery, professional associations, institutional research offices, community resources, experts, and practitioners).

- Uses surveys, letters, interviews, and other forms of inquiry to retrieve information as appropriate for the research area or discipline.

4. Refines the search strategy, if necessary.

Outcomes include:

The student:

- Assesses the quantity, quality, accuracy, currency, and relevance of the search results and the limitations of the information retrieval systems or investigative methods to determine whether alternatives should be sought and used.
- Identifies gaps in the information retrieved and determines if the search strategy should be revised.

- Repeats the search using the revised strategy or new systems or methods as necessary.

5. Extracts, records, transfers, and manages the information and its sources.

Outcomes include:

The student:

- Selects among various technologies the most appropriate one for the task of extracting the needed information (e.g., copy/paste software functions, photocopier, scanner, audiovisual equipment, exploratory instruments and export of information or record [to bibliographic software databases, Excel spreadsheets], or note taking).

- Creates a system for organizing the information.

- Differentiates between the types of sources cited and understands the elements and correct syntax of a citation for a wide range of resources.

- Records all pertinent citation information for future reference by downloading, printing, e-mailing, or manual notation and considers the use of bibliographic software for this purpose.

- Uses various technologies to manage the information selected and organized.

6. Consults experts for assistance and/or guidance when needed.

Outcomes include:

The student:

- Consults with instructor/advisor for appropriateness of topic or research question.

- Consults librarian or library staff if unable to identify or locate appropriate materials.

- Identifies subject experts to consult, as necessary.

\section{Standard three}

The information literate student critically evaluates the procured information and its sources, and, as a result, decides whether 
to modify the initial query and/or seek additional sources.

\section{Performance indicators}

The information literate student:

1. Summarizes the main ideas to be extracted from the information gathered.

Outcomes include:

The student:

- Understands how to read a scientific paper efficiently and can use sections, such as the abstract or conclusion, to decide whether to include the source.

- Selects main ideas from the text.

- Identifies verbatim material that can be then appropriately quoted.

2. Selects information by articulating and applying criteria for evaluating both the information and its sources.

Outcomes include:

The student:

- Recognizes where the information source appears in the flow of scientific information.

- Distinguishes among facts, points of view, and opinion.

- Examines and compares information from various sources in order to evaluate reliability, validity, accuracy, authority, timeliness, and point of view or bias.

- Analyzes the structure and logic of supporting arguments or methods.

- Understands and uses statistical treatment of data as evaluative criteria.

- Recognizes prejudice, deception, or manipulation in the information or its use.

- Recognizes the cultural, physical, or other context within which the information was created, and understands the impact of context on interpreting the information.

3. Synthesizes main ideas to construct new concepts.

Outcomes include:

The student:

- Recognizes interrelationships among concepts and combines them into potentially useful primary statements and/or summary of findings with supporting evidence.
- Extends initial synthesis, when possible, at a higher level of abstraction to construct new hypotheses that may require additional information.

- Utilizes computer and other technologies (e.g., spreadsheets, databases, multimedia, and audiovisual equipment) for studying the interaction of ideas and other phenomena.

4. Compares new knowledge with prior knowledge to determine the value added, contradictions, or other unique characteristics of the information.

Outcomes include:

The student:

- Determines whether information satisfies the research or other information need.

- Uses consciously selected criteria to determine whether the information contradicts or verifies information used from other sources.

- Draws conclusions based upon information gathered.

- Tests theories with discipline-appropriate techniques (e.g., simulators, experiments).

- Determines probable accuracy by questioning the source of the information, limitations of the information gathering tools or strategies, and the reasonableness of the conclusions.

- Integrates new information with previous information or knowledge.

- Determines whether information provides evidence for the information need or research question and which information does provide that evidence.

5. Determines whether the new knowledge has an impact on the individual's value system and takes steps to reconcile differences.

Outcomes include:

The student:

- Does not exclude or skew knowledge that is pertinent even when it impacts the individual's value system. 
6. Validates understanding and interpretation of the information through discourse with other individuals, small groups or teams, subject-area experts, and/or practitioners.

Outcomes include:

The student:

- Participates in classroom and other discussions.

- Works effectively in small groups or teams.

- Participates in class-sponsored electronic communication forums designed to encourage discourse on the topic (e.g., email, bulletin boards, chat rooms).
- Seeks expert opinion through a variety of mechanisms (e.g., interviews, e-mail, electronic lists).

7. Determines whether the initial query should be revised.

Outcomes include:

The student:

- Determines if original information need has been satisfied or if additional information is needed.

- Reviews search strategy and incorporates additional concepts as necessary.

\section{Works consulted in developing these standards}

In developing the standards, the task force reviewed six regional accreditation sources, standards and criteria for three disciplines, four monographs, engineering library information competencies, and a relevant university Web site:

- Middle States Association of Colleges and Schools, www.msache.org.

- North Central Association of Schools and Colleges-Higher Learning Commission, www.ncahigherlearningcommission.org/index.html.

- Northwest Association of Schools, Colleges and Universities, www.nwccu.org.

- Southern Association of Colleges and Schools, www.sacscoc.org.

- Western Association of Schools and Colleges, www.wascweb.org.

- NEASC: New England Association of Schools and Colleges-Commission on Institutions of Higher Education, www.neasc.org.

- National Environmental Health Science and Protection Accreditation Council, www. ehacoffice.org.

- Accreditation Board for Engineering and Technology, www.abet.org/criteria.html.

- American Chemical Society (ACS), Committee on Professional Training, 2003, Undergraduate Professional Education in Chemistry: Guidelines and Evaluation Procedures, Columbus, Ohio, American Chemical Society. Available at: www.chemistry.org/portal/a /c/s/1/acsdisplay.html?DOC=education $\backslash c p t \backslash$ guidelines.html.

- Engineering Libraries: Building Collections and Delivering Services, Conklin and Musser, eds., Haworth Press, Inc., NY 2001.

- ASEE Engineering Libraries Division, "Information Competencies for Engineering".

- Information and the Professional Scientist and Engineer, Baldwin and Hallmark, eds., Haworth Press, Inc, NY 2001, (Flaxbart, Joseph, Wild and Havener, Pinelli, Caracuzzo, Wagner).

- Online Ecological and Environmental Data, Baldwin, Virginia A., ed., Haworth Press, Inc, NY 2004.

- Communication Patterns of Engineers. Tenopir, Carol, and Donald W. King, IEEE Press (Wiley-Interscience), Piscataway, NJ 2004.

- Cal Poly University, "Introductory Competencies in Specific Disciplines," www.lib. calpoly.edu/infocomp/specific.html. 
- Reviews information retrieval sources used and expands to include others as needed.

8. Evaluates the product and the process. Outcomes include:

The student:

- Reviews the product and the process and determines possible improvements.

- Applies the improvements to subsequent projects.

\section{Standard four}

The information literate student understands and respects the economic, ethical, legal, and social issues surrounding the use of information and its technologies and, either as an individual or as a member of a group, uses information effectively to accomplish a specific purpose.

\section{Performance indicators}

The information literate student:

1. Understands many of the ethical, legal and socioeconomic issues surrounding information and information technology.

Outcomes include:

The student:

- Identifies and discusses issues related to privacy and security in both the print and electronic environments.

- Identifies and discusses issues related to free vs. fee-based access to information.

- Identifies and discusses issues related to censorship and freedom of speech.

- Demonstrates an understanding of intellectual property, copyright, and fair use of copyrighted material and research data.

2. Follows laws, regulations, institutional policies, and etiquette related to the access and use of information resources.

Outcomes include:

The student:

- Participates in electronic discussions following accepted practices (e.g., "Netiquette").

- Uses approved passwords and other forms of ID, ethically, for access to information resources.
- Complies with institutional policies on access to and distribution of information resources.

- Preserves the integrity of information resources, equipment, systems, and facilities.

- Legally obtains, stores, and disseminates text, data, images, or sounds.

- Demonstrates an understanding of what constitutes plagiarism and does not represent work attributable to others as his/her own. This includes the work of other members of research teams.

- Demonstrates an understanding of institutional policies related to human subjects research.

- Demonstrates an understanding of federal, state, and institutional policies related to using live animals in research.

3. Acknowledges the use of information sources in communicating the product or performance.

Outcomes include:

The student:

- Selects an appropriate documentation style for each research project and uses it consistently to cite sources.

- Posts permission granted notices, as needed, for copyrighted material.

- Acknowledges all contributors, funding sources, grants, etc.

4. Applies creativity effectively in use of the information for a particular product or performance.

Outcomes include:

The student:

- Selects, analyzes, organizes, summarizes, and/or synthesizes information from a variety of resources.

- Uses advanced information technologies, such as data mining and visualization to move beyond retrieval and identify trends and patterns within large sets of complex data.

5. Revises the development process for the product or performance.

Outcomes include:

The student: 
- Maintains a journal or log of activities related to the information-seeking, evaluating, and communicating process.

- Reflects on past successes, failures, and alternative strategies.

6. Communicates the product or performance effectively to others.

Outcomes include:

The student:

- Chooses a communication medium and format that best supports the purposes of the product or performance and the intended audience.

- Uses a range of information technology applications in creating the product or performance.

- Incorporates principles of design and communication.

- Communicates clearly and succinctly, if appropriate, with a style that supports the purposes of the intended audience.

\section{Standard five}

The information literate student recognizes the need to keep current regarding new developments in his or her field and understands that information literacy is an ongoing process and an important component of lifelong learning.

\section{Performance indicators}

The information literate student:

1. Understands that information searching requires time, diligence, and practice, and that skills are learned over time.

\section{Outcomes include:}

The student:

- Searches relevant resources diligently and with increasing accuracy over time.

2. Increases self-confidence with practice and experience in information seeking.

Outcomes include:

The student:

- Composes search statements using Boolean operators and limiting factors.

- Retrieves accurate information any time and from any source.
3. Appreciates that information literacy requires an ongoing assimilation of learning and information technologies.

Outcomes include:

The student:

- Recognizes that as a professional in a field, it will be necessary to keep up with new developments that are published in the literature of the field.

- Recognizes that learning about information gathering is an ongoing process as the source, format, software requirements, and delivery of needed information changes and evolves with time.

- Establishes current awareness services, follows citation and cited references for pertinent articles, scans online tables of contents, examines review journals and other forms of rapid communication literature, and manages files of citations of articles read or accessed (such as through use of bibliographic management software).

- Transfers information access skills to new subject areas.

- Uses bibliometric analysis tools to update knowledge of changing technology and product life cycles (such as by analyzing a company's published papers and/or patent portfolio).

- Keeps up with scholarly publishing changes in the field.

- Understands the importance of archiving information so that it will survive company mergers, outdated access technologies, personnel departures, and the like. $\boldsymbol{n}$

\section{ACRL standards and guidelines available online}

Online versions of draft and approved ACRL standards and guidelines are just a click away on the ACRL Web site. You can find the standards or guideline you need in an alphabetical listing or by topic area. Go to www.ala.org/acrl and click on "Standards and Guidelines" for a complete list of documents. 